\title{
WiSE Women of the UAE
}

\section{Dr. Nadia M Alhasani, The Petroelum Institute}

Dr. Nadia M. Alhasani, is Professor of Engineering and Applied Sciences, and founding Dean of the Women in Science and Engineering Program (WiSE) at the Petroleum Institute in Abu Dhabi. Completed her bachelor degree from the College of Engineering, University of Baghdad, and graduate degrees from MIT and the University of Pennsylvania. Held the position of assistant vice chancellor for academic affairs at the American University of Sharjah 2003-6, as well as teaching positions at the University of Pennsylvania, Miami of Florida, Notre Dame of Indiana, and Michigan. Recipient of the 2006-7 Research Fellow at the Aga Khan Program for Islamic Art and Architecture at MIT, 1990-91 Willard A. Oberdick Fellowship in the Building Sciences from the University of Michigan, 1992 Graham Foundation Grant, Chicago, and 1994 National ACSA Faculty Teaching Award, Washington DC. Lectured and published in the field of building production, technology and culture, higher education and women in STEM in the Middle East. 


\title{
WISE WOMEN of THE UAE
}

\begin{abstract}
Many observations have been documented, much research conducted and numerous arguments presented on the topic of Women in Science, Technology, Engineering and Mathematics (STEM). The Petroleum Institute's (PI) Women in Science and Engineering Program (WiSE), located in Abu Dhabi-United Arab Emirates (UAE), was established to meet a specific need, which is providing the local petroleum industry with a steady supply of qualified women engineers and scientists. It evolved to become a pioneering model for training women in applied science and technology, enabling them to become effective agents of change in the regional oil and gas industry. This study discusses the challenges met and the means in which management is overcoming the various hurdles, both global and local, towards building a community of young women engineers and scientists in a male-dominated profession and industry. In particular, the study addresses the means in which recruitment of high school students is overcoming the image of women enrolled in local STEM programs, retention is based on elevating the role of women in engineering and the local society to a higher status, and how the program's alumnae are enduring and progressing in the local oil and gas sector, both in the fields and headquarters.
\end{abstract}

\section{A General Overview}

In Fall 2006, the Petroleum Institute welcomed 104 Emirati high school graduates who made history as the first cohort of women enrolled in its undergraduate programs, joining the men who began their classes in Fall 2001. They pursued bachelor degrees in chemical engineering, electrical engineering, mechanical engineering, petroleum engineering and petroleum geosciences. Seven years later, the Women in Science and Engineering Program boosts over 400 students representing $35 \%$ of the total undergraduate population and almost 150 alumnae to date. These numbers are more impressive when considering the fact that most students are commuters as no women dormitories are currently available. Table I displays the steady increase in enrollment numbers by academic level and the percentage of women students against the total undergraduate student population. Of interest is the number of current juniors and seniors that approach $50 \%$ of the total undergraduate student population, a significant number compared to the US average of $15-20 \%$. 
Table I: History of Enrollment by Level and Percentage against Total Undergraduate Students

\begin{tabular}{|c|c|c|c|c|c|c|c|c|c|c|c|c|c|c|}
\hline $\begin{array}{c}\text { Academic } \\
\text { Level }\end{array}$ & Fall 2006 & \multicolumn{2}{|c|}{ Fall 2007} & \multicolumn{2}{|c|}{ Fall 2008} & \multicolumn{2}{c|}{ Fall 2009} & \multicolumn{2}{|c|}{ Fall 2010} & \multicolumn{2}{|c|}{ Fall 2011} & \multicolumn{2}{|c|}{ Fall 2012} \\
\hline $\begin{array}{c}\text { Foundation } \\
\text { / AUP }\end{array}$ & 104 & $22 \%$ & 170 & $37 \%$ & 153 & $38 \%$ & 106 & $38 \%$ & 91 & $27 \%$ & 69 & $20 \%$ & 111 & $30 \%$ \\
\hline Freshman & - & $0 \%$ & 37 & $24 \%$ & 66 & $46 \%$ & 65 & $40 \%$ & 60 & $42 \%$ & 80 & $37 \%$ & 92 & $27 \%$ \\
\hline Sophomore & - & $0 \%$ & 4 & $3 \%$ & 62 & $30 \%$ & 101 & $48 \%$ & 67 & $46 \%$ & 74 & $47 \%$ & 57 & $35 \%$ \\
\hline Junior & - & $0 \%$ & - & $0 \%$ & 2 & $2 \%$ & 54 & $33 \%$ & 84 & $44 \%$ & 73 & $45 \%$ & 69 & $50 \%$ \\
\hline Senior & - & $0 \%$ & - & $0 \%$ & - & $0 \%$ & 9 & $4 \%$ & 73 & $31 \%$ & 86 & $44 \%$ & 94 & $44 \%$ \\
\hline $\begin{array}{c}\text { Total } \\
\text { Students }\end{array}$ & 104 & $11 \%$ & 211 & $20 \%$ & 283 & $26 \%$ & 335 & $33 \%$ & 375 & $35 \%$ & 382 & $36 \%$ & 423 & $35 \%$ \\
\hline
\end{tabular}

\section{The Context of the UAE}

To better assess the level of conviction the founders and supporters of this Program have, it is necessary to study the context within which it was planned, developed, and supported. Over the past decade, the United Arab Emirates has pushed for a rapid development in both its infrastructure and its human capabilities. Two public documents are worth analyzing within this context, the UAE National Charter for 2021, and the Abu Dhabi Economic Vision 2030.

The UAE National Charter for $2021^{1}$, announced February 2010 and entitled United in Ambition and Determination was initiated as part of its preparation for the country's golden jubilee celebrations in 2021. It listed the dictum "United in Knowledge" as the third of its four principle themes, under which the subtitle reads "A competitive economy driven by knowledgeable and innovative Emiratis." The section's opening statement announces that: "We want all Emiratis to make a valuable contribution to their nation's growth by building their knowledge and applying their talent with innovation and drive."

With a national population of less than $20 \%$ of the total UAE population of over five million and heavy reliance on an imported labor force for all aspects of its economy, the importance of an educated national population becomes a strategic necessity for the operation and direction of the local economy. Therefore it is only natural for the country's leaders to tap into a vital resource, namely the UAE women.

Women in the UAE, as per the 2006 census, account for 49.4 per cent of the total population, represent 77 per cent of college students in the UAE, and earn 46 per cent of the degrees national earned from international institutions. More impressive is the fact that they represent 66 per cent of the government workforce with 30 per cent in senior positions and involved in decisionmaking. Fifteen percent are involved in technical jobs, medicine, nursing and pharmacy, and fifteen per cent in the armed forces, customs and police ${ }^{3 .}$ These numbers compare favorably with those of the US, as per the 2008 census, in which women account for 50.1 per cent of the total population, earn 60 per cent of college degrees and represent 46.7 per cent of the workforce.

The late Sheikh Zayed bin Sultan Al Nahyan, founder of the UAE, had stated that "Islam affords women their rightful status, and encourages them to work in all sectors, as long as they are 
afforded appropriate respect." This powerful statement became the basis for a serious commitment by the UAE federal government to afford women a level chance at filling high ranking positions in public offices. This policy accomplished two important goals: first it allowed qualified women a chance to serve their country at the highest levels; and second, it provided the women of the UAE, early in its modern history, effective role models to emulate. Between the period of 2004-2008, there were a number of major strategic appointments featuring women in positions never been occupied by women before. These included four ministers (secretaries), two ambassadors, one council general and nine members in the newly constituted Federal National Council. The latter appointments occupied 22.5 per cent of its membership. For comparison purposes, it is worth mentioning that Swiss women did not get to vote until 1971 and the first woman to be an official candidate for the Swiss National Council was in 1983. Thus the Emiratis' accomplishments to-date is quite significant given the fact that the state declared its independence in 1971.

The more significant accomplishment in these appointments is the breaking of a perceived glass ceiling and the evolution of many role models in diverse sectors of the UAE society (i.e. political, economic, legal, professional, etc.). Examples of such pioneering appointments include the appointment of the first Federal Judge and first General Registrar (both in 2008). Since then, women have sought and secured numerous atypical positions such as fighter jet and commercial airline pilots, seaport freight fork lift controllers, train operator, law enforcement officers, etc. Stereotypes in the professional fields have been replaced with numerous pioneering women moving through the career ladder at a very rapid speed.

A second important document, the Abu Dhabi Economic Vision $2030^{2}$, focuses on developing a knowledge-based economy. The document received advice and input from development consultants from Norway, Ireland and New Zealand; specifically, studying these countries' experiences in oil production and recovery, diversified knowledge-based economy, and an export base industry respectively. The document states that "the expectation was the creation of a longterm roadmap for economic progress for the Emirate through the establishment of a common framework aligning all policies and plans and fully engaging the private sector in their implementation."

The Abu Dhabi Economic Vision 2030 aspires to achieve tangible levels of economic diversification through dependency on a highly-skilled knowledge-based workforce focused on export-oriented sectors. These sectors include Energy (oil \& gas), Petrochemicals, Metal, Aviation, Aerospace, \& Defense, Pharmaceuticals, Biotechnology, \& Life Sciences, Tourism, Healthcare, Equipment \& Services, Transportation, Trade, \& Logistics, Education, Media, Financial Services, Telecommunication Services. In order to achieve this vision, it is necessary to seek qualified Emiratis, both men and women, to undertake the initiatives stated and contribute to the development planned.

To this end, the field is wide open for Emiratis to join the workforce and an abundance of support for them is readily available in line with the Emiratization initiative, by which the UAE Federal Government actively appoints nationals in meaningful positions both in the public and private sectors. So it comes as a surprise that there are some twelve thousand Emiratis searching for work, of which 84 percent are females ${ }^{4}$. More alarming is the findings of a recent study on 
women active in the region's labor force ${ }^{5}$. It confirmed that unemployed Emirati women have higher educational attainment than their male counterparts. So if the government is supporting women's employment, and women are educated, why are these unemployment numbers so high and persistent?

One major attribute to the widening gap between the need for a qualified national workforce and a want for a meaningful career path is the type of education and qualification a job-seeker has. Most of these unemployed nationals are holders of degrees in the humanities and social sciences, business and general higher diplomas. These general education degrees, while important in providing an education, are not preparing their holders for the local job market requirements. This is more evident when considering the expectations that Emiratis would fill white collar jobs and should be able to progress rapidly through an accelerated career path based on continuous training.

\section{Initiatives in Support of the Vision}

Over the past decade, the government has implemented a number of initiatives targeting the education sector in order to bridge the gap between degree attainment and the actual job market needs. One such initiative is the establishment of sector-specific institutions that educate and train Emiratis towards a highly skilled technical workforce. These include Masdar Institute of Science and Technology (MIST), Khalifa University of Science, Technology and Research (KUSTAR), Abu Dhabi Polytechnic, and the Petroleum Institute (PI). These academic institutions are currently being supported, both financially and logistically, to raise their profile within and outside the region, in order to attract the top international talent and expertise to prepare its graduates for a new type of workforce in the UAE. This model is very much in line with the South Korean model of education in which science, technology, engineering and mathematics are at the core of its curricula and economy.

The Petroleum Institute was established through an Emiri decree and is supported by the Abu Dhabi National Oil Company (ADNOC). This in itself is significant since this academic institution was the first of its kind established to address the needs of a sector-specific industry and its sponsors constitute a group of petroleum industry companies, both national and international (namely ADNOC, BP, Total, Shell and JODCO). Therefore the uniqueness of the PI stems from its focus on science and engineering with specific applications in the petroleum industry and energy sector at large. It continues to evolve through collaboration between academia, the government and energy industry. This is also the context within which our students are exposed to on a regular basis.

All members of the pioneer women cohort enrolled in a foundation year, housed in a standalone facility (known as Arzanah), where segregated course sections were opened parallel to those for the men. These pioneers were held to the same academic standards and professional expectations however under a different learning environment.

One clear indication of the quality of the curricula in place and its compatibility with north American curricula of similar focus is securing full accreditation by ABET accreditation 
(Accreditation Board for Engineering and Technology, Inc.). In addition to the academic implication this accreditation signifies, its award provided all involved with the outside endorsement that our current academic and operational practices and policies, while unorthodox, are not jeopardizing the quality of the education our undergraduate students are receiving given the fact that we are not a co-educational academic institution. The key to the success of the WiSE Program is the continuous focus on seeking a balance between gender-neutral knowledge and gender-specific practices.

The WiSE Program evolved rapidly over the past six years. It began as a women campus, then was designated as a college a few years later, and finally declared a program. It differs from other segregated science and engineering programs in the region in that minimal duplication in facilities, offices and staff is maintained. Instead, the operations are based on the development of purpose-specific staff positions and programs that cater to the particular needs of the women students and daily operations of the facility. A case in point is the Arzanah SOS Office. Rather than duplicating such offices as student affairs, finance, registrar, internship, parking, etc., a new office namely SOS Office (Student One-Stop Shop) was established to ensure students access to all types of support, whether academic, logistical or service. Since students are not able to regularly access the central offices on the main campus, this solution became an effective replacement in which the women students were able to attend to all their needs in one location. The success of this initiative, due to ease of access, prompted the men's side of the campus to replicate the initiative (even though all offices are readily available to the men students). In other words, what began as a need for the women students became a standard practice across campus.

\section{Challenges and Opportunities}

The uniqueness of the WiSE Program is integral to its success in recruiting talented high school students, retaining dedicated engineering and applied sciences degree candidates, and ensuring a workforce committed to the oil and gas industry. The women groups above must be targeted as three independent pools with distinct perceptions of what the study and profession of engineering and applied sciences are. Each group must be considered as a target group and thus be approached with a particular language and specific programs. If we consider a "divide and conquer" approach to the issue of women in STEM studies and professions, it becomes easier to isolate the problems, find a solution and address the low enrollment and lower retention numbers.

The first problem addressed by the PI WiSE Program is that of the profession's image. Unlike medicine, engineering as a major and profession is perceived to be difficult rather than challenging, dry rather than stimulating, and dreary rather than rewarding. Women do not seem to mind the medical field's long years of study, hard training and difficult working hours. Nor do they ponder, at least in the case of the UAE, the nature of the work environment in which men and women are expected to work together for long hours and under a lot of pressure. The medical field has idealized their profession by focusing on the noble goal of serving humanity and treating the sick. This very notion has been lost on engineering and the sciences. In a similar manner, when recruiting students from high schools, the focus of the PI presentation is on the softer aspects of engineering such as accessibility to everyone, application in life saving 
solutions, making our daily living less taxing, etc. Providing examples in which engineering is an integral part of a woman's daily routine (such as use of make-up, mobiles, hair dryers, etc.) or focusing on a woman's sensibility in seeking practical solutions for simple but persisting issues are an integral theme of such presentations. A case in point is Temple Grandin who is a good example to consider as she turned the inhumane process of slaughtering cattle into a humane and profitable process through invention and innovation.

The second problem addressed by the WiSE Program is that of stereotyping engineering and science students. Given the integral role of tradition in the UAE society, and in spite of the strong presence of globalization, the reliance on cultural norms is very much part of the Program's commitment to strengthen the presence of the Emirati identity both in spirit and practice. By combining a need for volunteering and a want for hospitality the program Arzanah Ambassadors was created. Students are more than the typical college ambassadors. They are representatives of the women in the UAE first and then PI engineering students. They prepare presentations highlighting the various aspects of the UAE, discussing such topics as education and customs, traditional dress and cuisine, among other topics. These Ambassadors invite foreign students, lead VIP delegations and host gatherings for expatriate women living in the area. These activities are intended to instill in the students their identity as women being an integral part of the UAE society while providing them with opportunities to become abled leaders working with any and all types of people. This strong commitment to local values and cultural traditions is diagonally opposed to the popular image of an engineering school seeped in science, innovation, and high tech images. It also provides them with the opportunity to be admired and respected by others. This in turn boosts a student's confidence and commitment to their chosen profession.

A similar philosophy is applied to the type of non-instructional spaces developed for the women. From study rooms to student lounges, exercise halls to game rooms, all are developed as personalized rather than institutionalized spaces, reflecting the way the young generation is able to handle the want for advanced technology and the need for comfortable spaces. Spaces are designed with the young women in mind. They exhibit splashes of color, extensive art work and non-traditional furniture. Quiet spaces are complemented with "sukoon" and "mummy's" rooms dedicated to short naps and breast-feeding simultaneously.

The third and final problem addressed by the WiSE Program is the issue of working in a maledominated industry like the oil and gas industry especially in the Middle East. While this issue seems to be the same in most countries, it is quite different for the PI since all our students are expected to work for the local oil and gas industry. This fact alone, while adds to the challenges of recruitment, makes it easier for the WiSE management to isolate the relevant issues that would face a women engineer working in the petroleum industry, address them in collaboration with the companies that will receive our alumnae, and seek lasting solutions to address the possible "leaking pipeline" (referring to the petroleum industry's problem of low retention among its workforce) prior to it becoming a threat to its workforce. Thus what might be considered a challenge can easily become an opportunity. Since the Program's early years, it became standard practice to get students wearing their industry safety gear, even to teaching labs, to get the women comfortable working in them. This coupled with frequent trips to the oil fields, power plants, and industry training facilities and completing internships and training programs in 
petroleum-related companies, broke the barrier in terms of access to industry sites and companies. These sites also became accustomed to having large number of women engineers frequent their facilities and it quickly became a normal occurrence (most of these sites now accommodate for women lavatories and other support facilities). This was further strengthened by the fact that most students, by the time they graduate, are familiar with the industry's key personnel, processes, and terminology. The Program receives tremendous support from the academic programs as they begin early in the curriculum their introduction to the industry by providing examples from the industry and assigning actual projects that students can seek data or advise from one of the sponsoring companies. Not unlike the medical field, once an intern specializes in a certain field, there develops a bond between the individual and a particular group of similar interests. So that by the time our alumnae are ready to join the workforce, they are eager to become part of a team they are already acquainted with.

The three problems discussed are at the core of the daily operations of the WiSE Program and the focus of its mission which "seeks to promote women's education attainment, professional aspirations, social responsibility and personal growth," and its vision which "aspires to develop successful female engineers who make meaningful contribution to the profession and society at large." As discussed, the Program has developed into a unique model in which it operates with a focus on enrollment management (both recruitment and retention), academic and professional support, student affairs (extra curricula activities and counseling), and alumnae affairs (relations and support).

\section{Lessons Learned}

Over the past two years, the Petroleum Institute has celebrated the graduation of two WiSE cohorts with almost 150 alumnae in engineering and petroleum geosciences. More impressive is the comparative numbers within Class of ' 12 in which the women represented 47 per cent of the graduating undergraduate. These numbers are indicative of the progress made in retention.

An initial study on the current appointment and progress of the alumnae has indicated an overwhelming number joining the industry, with 23 per cent enrolled in graduate studies on a part-time basis. Only 5 per cent are currently pursuing their graduate studies on a full time basis (most in the US). These numbers alone reinforced the program's success in preparing a group of women engineers and scientists who are committed to the industry and their profession. By furthering their studies in their original major or a field related to their work, they are securing their future towards a career in the petroleum industry. To-date, only two per cent of the alumnae have opted to change careers. These numbers are quite encouraging and a positive indication of the intended outcomes of the program. By Summer 2013, the pioneer alumnae (Class of '11) would have completed two years in their professional careers and would be in a better position to provide feedback as well as gauge their professional satisfaction.

In a study on the variables influencing women's aspirations and access to educational leadership, two clear forces were emphasized, a woman's personal aspirations and her access to education. ${ }^{6}$ Our students have expressed their aspirations in joining a committed community of future women engineers and scientists, and are further "enticed" by inviting accomplished alumnae to share with them their path to success. By identifying with these young role models who have just 
been through the same path they are about to take, it becomes easier for management to train these young students into future leaders, an important component to ensure their retention within the Program and commitment to the profession once they graduate. Providing access is of significance to the students' success. Whether it is access to facilities, programs, know-how, or even opportunities, the Program's self-mandate is to "seeks to promote women's education attainment" and "professional aspirations." The Program is about identifying and facilitating access to any opportunity deemed helpful in paving a young woman's professional path.

\section{Conclusion}

Numerous academic institutions worldwide are scrambling to find ways to recruit women and minority to their engineering and science programs. All are in agreement that this segment of high school graduates continues to be an untapped resource. Additional efforts are concentrated on finding ways to increase retention within the engineering programs. In the UAE, these issues have been elevated to the federal level ensuring the full support of the government at large. The Petroleum Institute's Women in Science and Engineering Program was established to address a strategic need to increase the number of Emirati women filling technical positions in its petroleum industry.

The Program, a unique initiative, became an experimental ground to recruit, train and retain women in specific engineering disciplines with a particular focus on the local oil and gas industry. While the academic curricula are similar to those in North America, all other aspects of the program are planned and developed to ensure alignment with the mandate of the program while adhering to the society's deep-rooted traditions and cultural norms. The combination of particular operation procedures and policies, atypical facilities provided, and customized programs (academic, professional and recreational) have provided for a highly integrated community of students and alumnae providing each other with moral support and encouragement. Future studies will address quantitative and qualitative surveys to be conducted within the next twelve months to assess the outcomes of the Program with particular feedback from the alumnae and their employers.

In spite of its young age (seven years since establishment) and comparatively small number of alumnae (almost 150 in two years), the Program has developed as a regional leader in engineering education for women. More importantly, it has succeeded in its mandate of providing a steady stream of qualified women engineers to work in the local oil and gas industry. Early indications from the partner operating companies, in which our alumnae are actively employed, suggests a committed women workforce that is eager to learn, ready to work in the fields, and willing to take responsibilities. More importantly, the first cohort has completed almost two years in their positions with no one showing signs of quitting or changing career paths. On the contrary, anecdotal feedback suggests a highly motivated and well qualified group of young women engineers breaking grounds in various technical departments.

The current standing of the Program's students and alumnae brings to mind the story of "Rosie the Riveter." By mid 1940s, women in the US workforce increased by more than fifty per cent in response to the Government's call to work in non-traditional jobs in male-dominated industries. While many focus on the feminist agenda implied in this campaign, it is the breaking of the 
stereotyping and proving one's worth in contributing to a country's economy, especially during strategic phases in its evolution, that displays some communality with the UAE's current situation. It is this calling, to serve the UAE and Abu Dhabi society, which the WiSE women are responding to. His Highness Sheikh Khalifa bin Zayed Al Nahyan, President of the UAE and Ruler of Abu Dhabi, affirms that: "Work is a true criterion of citizenship. It is evidence of sincerity and loyalty. We all share the responsibility of building this country, protecting its sovereignty and safeguarding the gains." This call seems to bring the best out in our WiSE students and alumnae.

\section{References}

1. United in Ambition and Determinations, (2011). Abu Dhabi, UAE: UAE Federal Government.

2. Abu Dhabi Economic Vision 2030, (2009). Abu Dhabi, UAE: Abu Dhabi Council for Economic Development.

3. Al Serkal, Mariam. "Emirati women rise to the challenge," Gulf News, June 3, 2012-section A, page 15.

4. Al Ittihad, May $1^{\text {st }} 2010$, " $84 \%$ of job seekers are females".

5. BOOZ \& Company, Inc., Educated, Ambitious, Essential: Women Will Drive the GCC's Future, (2011).

6. Sperandio, Jill. "Creating and supporting women's leadership in education: Charting the effects of international, national and organizational cultures," in Gender Equality in Education: Looking beyond Parity. (An IIEP-based Policy Forum, 3-4 October, 2011, Paris). 